Article

\title{
Synthetic Aggregates for the Production of Innovative Low Impact Porous Layers for Urban Pavements
}

\author{
Piergiorgio Tataranni * and Cesare Sangiorgi ${ }^{(D)}$ \\ Department of Civil, Chemical, Environmental, and Materials Engineering, University of Bologna, \\ 40136 Bologna, Italy \\ * Correspondence: piergiorg.tataranni2@unibo.it
}

Received: 28 June 2019; Accepted: 3 August 2019; Published: 6 August 2019

\begin{abstract}
According to the latest estimates, $40 \%$ of urban areas are covered by pavements. One of the most remarkable effects on the urban environment is the increase in impermeable surfaces which leads to problems related to water infiltration into the ground and the increase in wash-off volumes. The use of permeable and porous layers in urban applications for cycle lanes, footpaths and parking areas is growing in interest, increasing the potential for control and management of urban runoff. In this paper, a physical and mechanical characterization is proposed of an innovative mixture, prepared with a polymeric transparent binder for semi-porous layers with reduced contribution to the urban heat island effect. Two versions of this mixture are compared, one with just virgin and the one with artificial synthetic aggregates, produced through the alkali-activation of waste basalt powder. Results show suitable properties for both materials if compared to porous asphalt concretes in traditional pavements. Furthermore, the application of synthetic aggregates seems to be a viable solution for the production of innovative and eco-friendly mixtures, allowing the recycling of waste materials.
\end{abstract}

Keywords: permeable pavements; porous asphalt concrete; polymeric transparent binder; synthetic aggregates; urban pavements; urban runoff

\section{Introduction and Objective}

According to the latest estimates, the expansion levels imposed by modern society will involve a dramatic growth in the size of cities by the middle of this century [1]. Today, urban areas are formed by multiple paved areas that facilitate people's daily mobility in different ways. From this perspective, pavements can no longer be considered as simple structures to connect places, since they are composed of roads, special lanes, bike lanes, footpaths and squares in which people spend a great part of their life. This rapid development presents challenges in terms of urban and environmental planning, considering that today $40 \%$ of urban areas are covered by pavements. This urban land-cover change is affecting the local ecosystems and the underlying surface conditions, resulting in an important increase in the portion of impervious surfaces. The natural hydrological process may be irreversibly changed [2,3], as a consequence of limited rainwater infiltration and the increased surface runoff [4]. Studies have demonstrated a clear correlation between increased flooding hazard registered in urban areas and the changes in the natural drainage network $[5,6]$. The growth of impervious surfaces has increased the runoff peaks as well as the stormwater runoff accumulation. From an environmental perspective, these impervious areas promote the stagnation of water containing urban pollutants such as road-deposited sediments and potentially toxic metals and metalloids. Studies demonstrated that the presence of contaminants is mainly related to the different land use: high quantities of polycyclic aromatic hydrocarbons were detected in some commercial sites, due to higher vehicle concentrations. Furthermore, heavy metals characterize the stormwater runoff from industrial land-use areas $[7,8]$. The presence of these pollutants can be considered as one of the primary contributors to water quality 
depletion in natural water bodies [9]. By 2030 the urban land cover will increase by 1.2 million $\mathrm{km}^{2}$ and according to recent studies, the global urban land cover is expected to be over $200 \%$ if compared to year 2000 [10].

Engineers from all over the world are facing the new challenges in managing the urban planning for a sustainable future. The importance of taking decisive actions to tackle these problems is obvious. From an environmental point of view, Best Management Practices (BMPs) are today widely applied as runoff control system in urban areas in order to reduce the so-called nonpoint source (NPS) pollution [11]. BMPs promote the development of detention basins and extended detention basins, which act as storage and water treatment areas. The latest research has highlighted the performance of innovative "smart" BMPs improved with a real-time active control of the stormwater detention basin outflows, able to achieve up to $90 \%$ of pollutant removal and considerably reduce the outflows volumes [12].

As for the increased wash-off volumes in urban areas, some countries have developed a series of guidelines and stormwater management plans and proposed some specific techniques to monitor the urban flooding. To date, the most effective method to control urban runoff is based on the urban design that promotes the development of permeable pavements and surfaces and green areas. This approach is traditionally counted among the infiltration-based technologies to control the urban runoff [13].

Permeable pavements can be considered as a suitable and sustainable alternative to traditional pavements produced with common asphalt or cement concrete. Considering that paved surfaces represent around the $25 \%$ of impervious urban surfaces, the possibility of using porous pavements can be effective in controlling the urban runoff $[14,15]$. Several studies demonstrated that porous pavements are considerably more effective in reducing the wash-off volumes if compared to drainage surfaces [16]. Moreover, the efficiency of these permeable surfaces is highlighted considering their contribution in decreasing the flood peak and its hysteresis, which is generally related to the thickness of the porous structure [17]. Starting from the traditional porous asphalts or concretes, some now materials such as modular elements, paving blocks or plastic grid system are today widely used in urban areas to create permeable areas and structures [18,19].

The porous layers are also effective against the Urban Heat Island (UHI) effect [20]. This phenomenon is another consequence of the dramatic development of urbanization and is evaluated as the overheating of urban temperatures compared to the relatively colder conditions of suburban zones and rural areas [21]. The traditional materials used for pavements and roofs absorb and store most of the solar energy falling on their surface during the day, which is then released in the form of heat during night-time. The albedo is the measure of the sunlight reflection of a surface out of the total solar radiation, and it ranges between zero (corresponding to a full absorption) and 100 (representing a completely reflective surface). The dark surfaces that traditionally distinguish the road pavements and roofs are characterized by a sunlight reflection up to 20\% [22]. Several studies and applications have been carried out to face the UHI through the adoption of innovative materials or simply increasing the solar reflection of surfaces $[23,24]$. Researches verified the mitigation of UHI through the use of porous mixtures and light-colored surfaces [25].

In the case study presented in this paper, a semi-porous mixture prepared with a polymeric transparent binder and a pale limestone aggregate is proposed. This innovative and eco-friendly material has the dual target of reducing urban runoff and UHI, by coupling a porous structure with a light-colored pavement surface. Moreover, the proposed material can be used as surface layer for the construction of a water-retaining pavement, which is a novel type of cool pavement [26]. In this case, the reduction in the pavement temperature is promoted by the evaporation cooling of water stored in the thickness of the layer.

Furthermore, the sustainability impact of this material is optimized by the partial substitution of natural aggregates with artificial synthetic aggregate produced through the alkali-activation of waste basalt powder. 


\section{Materials and Methods}

After reviewing some Italian technical specifications for semi-porous asphalt concretes, two mixtures were studied: one made with $100 \%$ pale limestone aggregates (SPT) and one with the replacement by $21 \%$ of virgin material with synthetic aggregates (SPS) produced through the alkali-activation of basalt waste powder.

\subsection{Polymeric Binder}

The polymeric material used as binder is a commercial single-component polyolefin resin sold in solid form (chips). It is used to produce conglomerates for low visual impact pavements to preserve the aesthetic of rural, residential or historical areas. Compared to other colored asphalt concretes, no pigment or additive is added to the original mixture. In this case the binder is transparent, so the final color of the material will be the given by the natural color of the aggregates used for the mix design. This allow to perfectly integrate the pavement in the surrounding landscape.

In operational terms, the binder is added at ambient temperature into the drum mix of a common asphalt plant, where it melts using the aggregates' heat. Once mixed, the material is laid down and compacted with the same technologies and methodologies adopted for common asphalt concretes. The properties of the binder are presented in Table 1 where the technical parameters are assessed in compliance with tests traditionally used for the characterization of bitumen for asphalt concretes.

Table 1. Technical properties of the polymeric binder.

\begin{tabular}{ccc}
\hline Technical Features & Typical Values & Reference Standard \\
\hline Dynamic viscosity at $160{ }^{\circ} \mathrm{C}$ & $>700 \mathrm{mPa} \cdot \mathrm{s}$ & EN 13702 \\
Penetration at $25^{\circ} \mathrm{C}$ & $25-55 \mathrm{dmm}$ & EN 1426 \\
Softening point & $>75{ }^{\circ} \mathrm{C}$ & EN 1427 \\
Flash point & $>220^{\circ} \mathrm{C}$ & DIN 51755, ASTM D92,D93 \\
Density at $25^{\circ} \mathrm{C}$ & $850 \mathrm{~kg} / \mathrm{m}^{3}$ & EN ISO 3838 \\
\hline
\end{tabular}

\subsection{Synthetic Aggregates}

The synthetic artificial aggregates were produced using the alkali-activation process. This is a chemical reaction that is established between two groups of materials, namely precursors and activators, with specific chemical properties. The former are materials generally rich in silica and alumina, the latter are needed to promote the chemical reaction. The result of the synthesis process is the development of a hardened binder based on a combination of hydrous alkali-aluminosilicate and/or alkali-alkali earth-aluminosilicate phases [27-29]. In the work presented in this paper, a specific mix of waste basalt powder and metakaolin was used as the precursor.

The basalt powder is a waste material completely passing the $50 \mu \mathrm{m}$ sieve resulting from the extraction and production processes in a basalt quarry. The use of basalt is not new for the alkali-activated materials, considering that its chemical properties are suitable for the synthesis reaction [30].

The metakaolin is obtained by heat treatment (around $700^{\circ} \mathrm{C}$ ) of a natural kaolin and its application to produce alkali-activated materials is a common practice. It is today well-known the improvement in the mechanical properties of the final mixture conferred by the presence of metakaolin [31]. Table 2 summarizes the chemical composition of both basalt and metakaolin powders.

The activators are needed to create a high alkaline ambient to develop the synthesis of the material. In the case under study a liquid compound of Sodium Silicate $\left(\mathrm{SiO}_{2} / \mathrm{Na}_{2} \mathrm{O}\right.$ ratio of 1.99) and Sodium Hydroxide $(10 \mathrm{M})$, mixed according to a specific dosage $(\mathrm{SS} / \mathrm{SH}=4)$, was used as the activator. After the mixing phase of precursor and activators, the material was handcrafted to produce granular samples and then cured for 12 hours in an oven at $60^{\circ} \mathrm{C}$. Some mechanical and physical tests were carried out on the synthetic paste and aggregates in order to characterize the material. 
As suggested by the well-established literature in the alkali-activated material field, the evaluation of the mechanical properties was based on the assessment of the compressive strength of the alkali-activated mixture. Considering the absence of specific test procedures for the mechanical analysis of this type of synthetic material, the EN 1015-11 [32] standard was taken as reference. According to the standard, the compressive strength of a hardened mortar is evaluated applying a load without shock and increasing it continuously at a rate within the range $50 \mathrm{~N} / \mathrm{s}$ to $500 \mathrm{~N} / \mathrm{s}$ so that failure occurs within a period of 30 to 90 second. The maximum load is registered and the compressive strength is than calculated. Furthermore, in order to evaluate the development of the mechanical properties of the mixture during the curing period, the compressive strength tests were repeated after 3, 7, 14, 21 and 28 days after the mixing and casting procedures. In compliance with the standard, tests were carried out on $40 \times 40 \times 40 \mathrm{~mm}$ cubic samples.

Table 2. Chemical properties of basalt and metakaolin.

\begin{tabular}{cccc}
\hline Compound & Unit & Basalt & Metakaolin \\
\hline $\mathrm{SiO}_{2}$ & $\% \mathrm{p} / \mathrm{p}$ & 45.3 & 55.2 \\
$\mathrm{CaO}$ & $\% \mathrm{p} / \mathrm{p}$ & 8.8 & 0.2 \\
$\mathrm{Na} 2 \mathrm{O}$ & $\% \mathrm{p} / \mathrm{p}$ & 1.7 & 0.6 \\
$\mathrm{Al}_{2} \mathrm{O}_{3}$ & $\% \mathrm{p} / \mathrm{p}$ & 21.6 & 40.3 \\
$\mathrm{Fe}_{2} \mathrm{O}_{3}$ & $\% \mathrm{p} / \mathrm{p}$ & $<0.1$ & 1.4 \\
$\mathrm{SO}_{3}$ & $\% \mathrm{p} / \mathrm{p}$ & 2.0 & 0.2 \\
$\mathrm{MgO}$ & $\% \mathrm{p} / \mathrm{p}$ & 0.7 & 0.1 \\
$\mathrm{P}_{2} \mathrm{O}_{5}$ & $\% \mathrm{p} / \mathrm{p}$ & 0.2 & $<0.1$ \\
$\mathrm{TiO}_{2}$ & $\% \mathrm{p} / \mathrm{p}$ & $<0.1$ & $<0.1$ \\
$\mathrm{ZnO}$ & $\% \mathrm{p} / \mathrm{p}$ & 9.7 & 0.2 \\
$\mathrm{~K}_{2} \mathrm{O}$ & $\% \mathrm{p} / \mathrm{p}$ & & \\
\hline
\end{tabular}

Four samples were tested for each test repetition and the average results are presented in Figure 1.

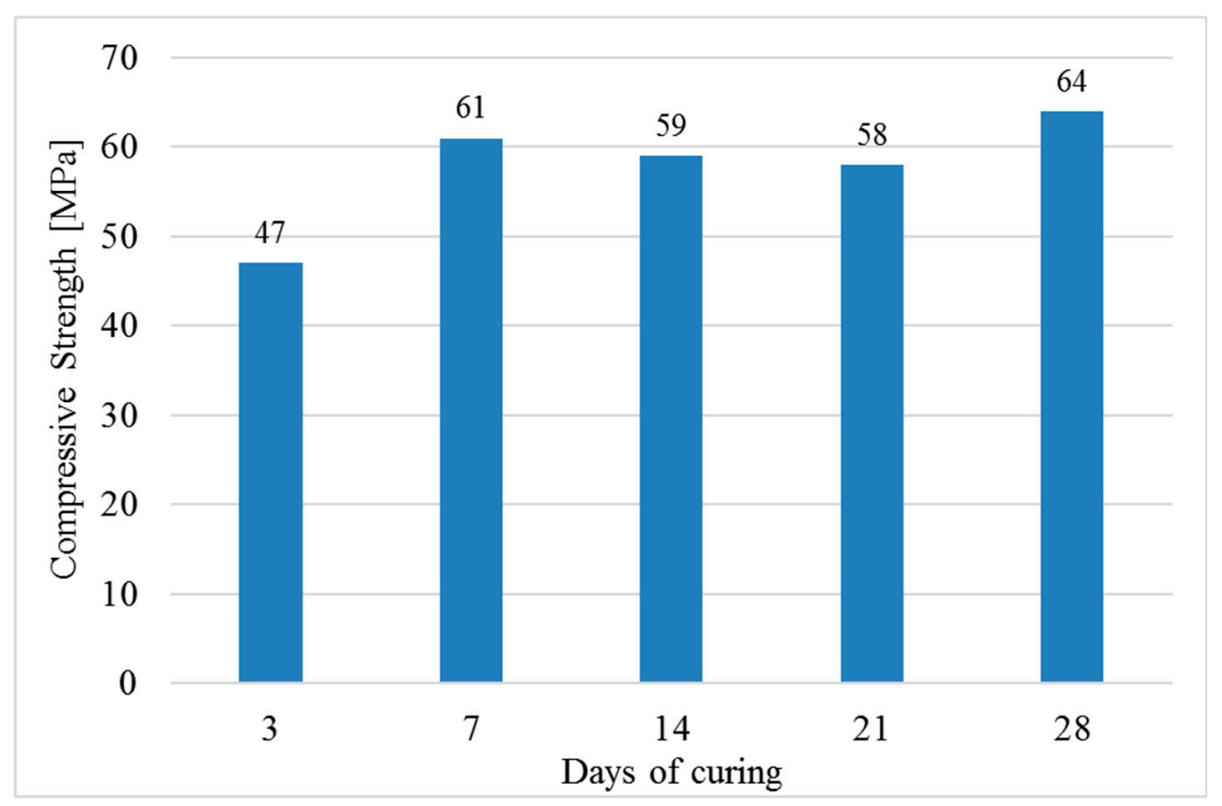

Figure 1. Compressive strength on alkali-activated mixture samples after 3, 7, 14, 21 and 28 days of curing.

Results in Figure 1 highlighted the achievement of a considerable compressive strength (47 MPa) just after 3 days of curing. From day 7 to day 28, there is visible a slight variation in results, ranging from 58 to $65 \mathrm{MPa}$. This phenomenon is quite common for the alkali-activated materials and it is 
mainly related to the high influence of the mixing and casting procedures on the final properties of the material. Hence, the curing procedure can be considered ended after 7 days and the compressive strength achieved is considerably high.

\subsection{Experimental Program}

The experimental program was divided in several laboratory phases, with the final aim of defining the physical, mechanical and functional properties of the two semi-porous mixtures.

Taking as a reference Italian technical specifications for semi-porous asphalt concretes, the physical characterization was based on the evaluation of the air voids content for samples prepared through gyratory compaction in accordance with the EN 12697-31 [33] standard (compaction pressure of $600 \mathrm{kPa}$ and 80 gyrations). The physical analysis was then supported by means of the Indirect Tensile Strength (ITS, EN 12697-23) [34] test carried out at $25^{\circ} \mathrm{C}$. The mechanical characterization was based on evaluation of dynamic behavior using the Indirect Tensile Stiffness Modulus (ITSM, EN 12697-26 annex C) [35] test. This was repeated at 10,20 and $30^{\circ} \mathrm{C}$ to check the thermal sensitivity of the two mixtures. Considering the porous structure of the material, the durability was assessed in terms of reduction of ITS (ITSR, EN 12697-12) [36] after freeze and thaw cycles and in terms of raveling resistance using the Cantabro test (EN 12697-17) [37]. The functional properties of the experimental mixtures were then evaluated as vertical permeability (EN 12697-19) [38] and skid resistance (EN 13036-4) [39].

\section{Mixtures Characterization}

\subsection{Mixture's Details}

Two mixtures were designed in compliance with a gradation band suggested by Italian technical specifications for semi-porous layers. The SPT mix was produced with $100 \%$ pale limestone aggregates. The SPS mix replaced $21 \%$ of the natural aggregate with synthetic aggregates (Figure 2).

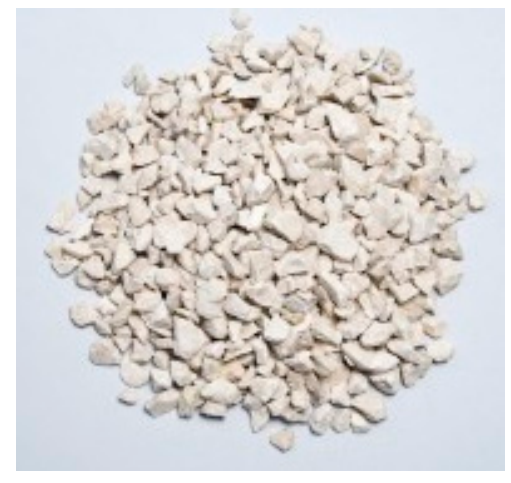

(a)

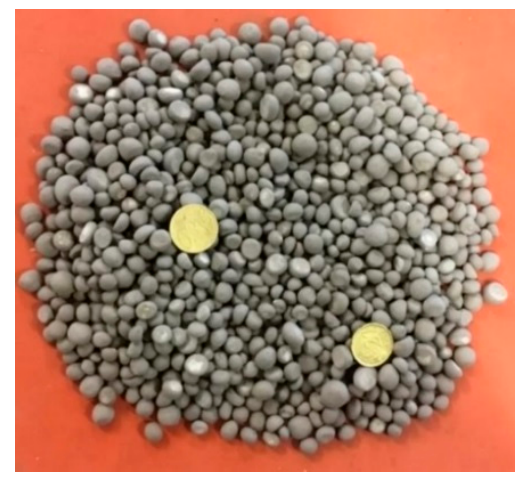

(b)

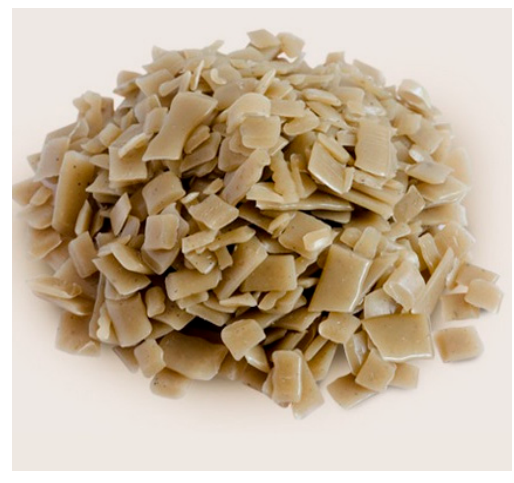

(c)

Figure 2. Pale limestone aggregates (a), synthetic aggregates (b) and transparent polymeric binder (c).

The synthetic aggregates were sieved in order to substitute only the natural aggregate particles with the same dimensions $(6.3 / 12.5 \mathrm{~mm})$. Therefore, the gradations of the two mixtures were kept constant in order to have comparable grading curves (Figure 3). After several laboratory trials, the optimum binder content was determined to be $5.5 \%$ by weight of the aggregates. In this case, the evaluation of the optimum binder content was carried out in compliance with the Marshall mix design method [40]. The mixing procedure provided for the heating of aggregates at $170{ }^{\circ} \mathrm{C}$ and the addition of the polymeric binder chips at ambient temperature directly into the laboratory mixer together with the hot aggregates. 


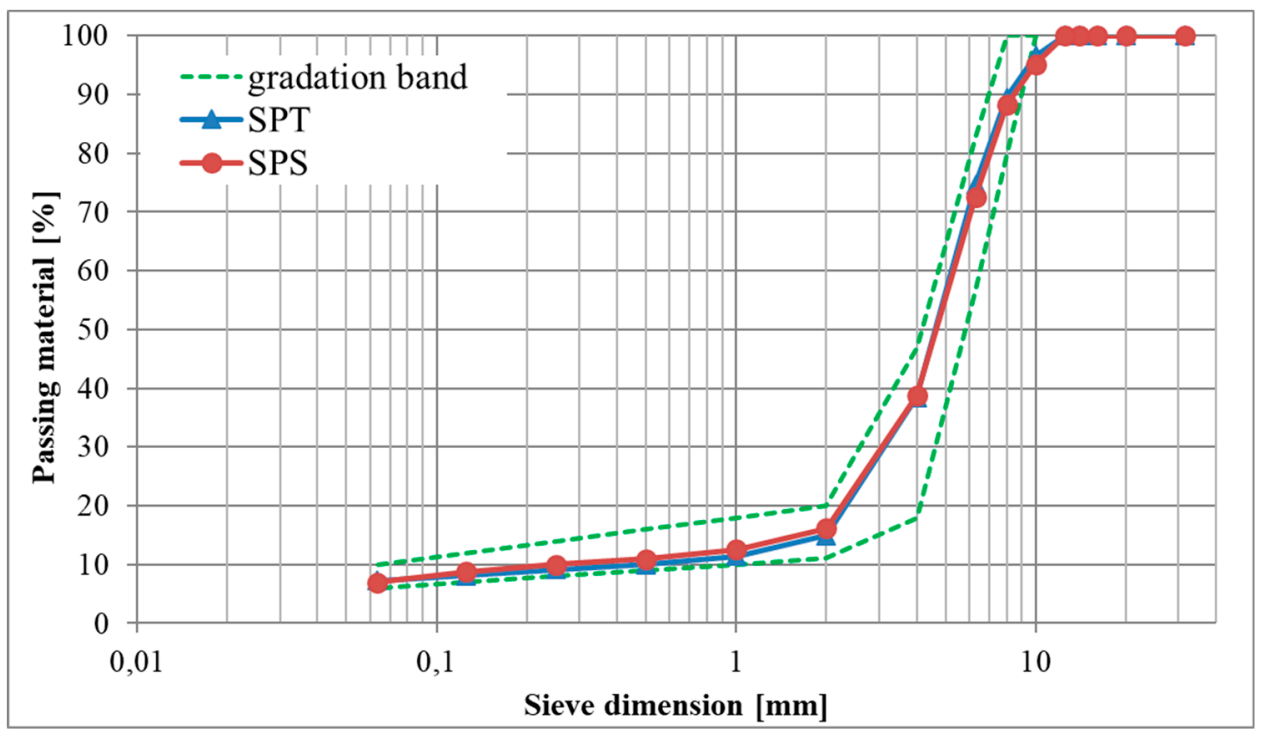

Figure 3. SPT and SPS particles distributions and gradation limits.

As showed in Figure 3, both the grading distributions fit the reference gradation band and there is no remarkable difference between the two mixtures.

The final aspect of the samples after compaction and its surface texture as well as the porous structure are shown in Figure 4. From a visual analysis the synthetic aggregates seem to be well distributed into the mixture, highlighting no issues in terms of workability and segregation during the mixing and compaction process.

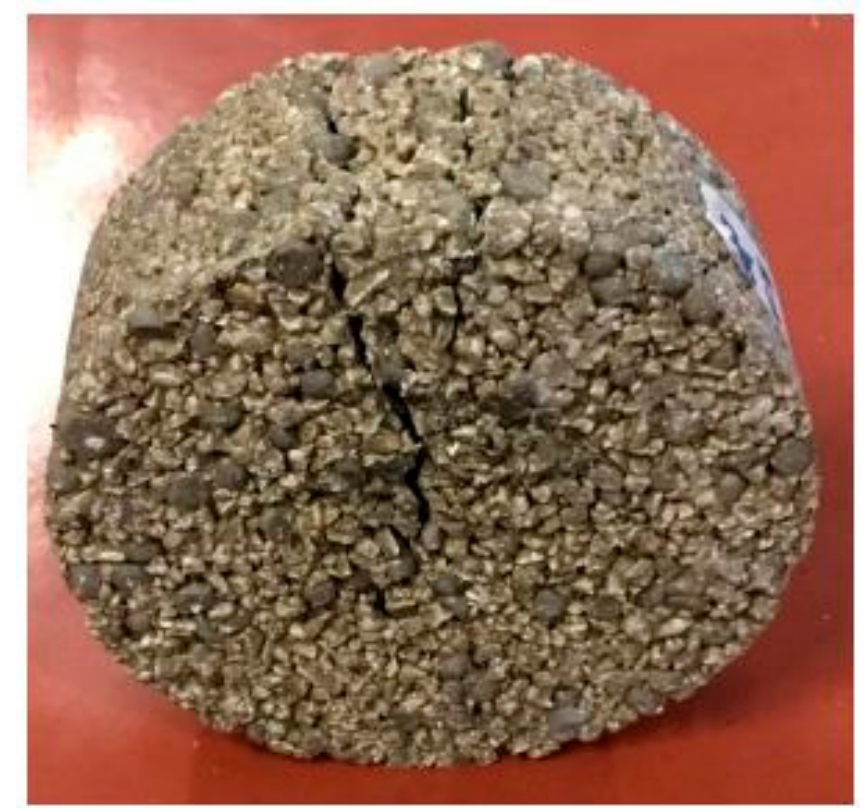

Figure 4. Gyratory sample with synthetic aggregates.

\subsection{Air Voids Content}

In order to verify the quality of the mix design, the air voids (Av) content (EN 12697-8) [41] was evaluated for the two experimental mixtures. Four gyratory samples were produced for each mix in compliance with EN 12697-31 standard (80 gyrations). The bulk density of the specimens was calculated using the geometrical procedure, as suggested by the EN 12697-6 [42] standard for open graded bituminous mixtures. The results are presented in Table 3. 
Table 3. Air voids content.

\begin{tabular}{cccc}
\hline Mixture & Av (\%) & Mixture & Av (\%) \\
\hline SPT_1 & 23.7 & SPS_1 & 26.3 \\
SPT_2 & 23.8 & SPS_2 & 26.5 \\
SPT_3 & 23.3 & SPS_3 & 26.6 \\
SPT_4 & 23.6 & SPS_4 & 27.3 \\
Avg. & $\mathbf{2 3 . 6}$ & Avg. & $\mathbf{2 6 . 7}$ \\
\hline
\end{tabular}

Both mixtures show a significant Av content. It is worth noting that the Italian technical specification suggests a lower Av limit of $16 \%$ for semi-porous mixtures. The remarkable porosity of the mixture is probably related to the adopted particles size distribution, which was close the lower limit of the gradation band for the material passing the $1 \mathrm{~mm}$ sieve and to the upper limit for the retained material at $4 \mathrm{~mm}$ sieve. In this case, the obtained aggregates distribution is more open graded.

The higher Av content for the SPS mixture is probably related to the rounded shape of the handcrafted artificial aggregates.

\subsection{Mechanical Characterization: ITS and ITSM}

The mechanical characterization was based on both static and dynamic tests: Indirect Tensile Strength (ITS) and Indirect Tensile Stiffness Modulus (ITSM).

The ITS test is generally useful for evaluation of the strength of cohesion between aggregates and mastic [43]. According to EN 12697-23, a load with a constant velocity of $50 \mathrm{~mm} / \mathrm{min}$ is applied diametrically to a cylindrical specimen until failure.

The test was carried out using 3 gyratory specimens ( 80 gyrations) conditioned at $25^{\circ} \mathrm{C}$ for 4 hours. The results are shown in Table 4 . Both experimental mixtures comply with the minimum ITS value suggested by the reference technical specification (ITS $\geq 0.50 \mathrm{MPa}$ ). The SPS mix shows better performance despite its higher porous structure. In wider terms, a suitable ITS is reached despite the considerable amount of air voids content in the mixtures.

Table 4. Indirect Tensile Strength (ITS) test results.

\begin{tabular}{cccc}
\hline Mixture & ITS (MPa) & Mixture & ITS (MPa) \\
\hline SPT_1 & 0.48 & SPS_1 & 0.55 \\
SPT_2 & 0.50 & SPS_2 & 0.60 \\
SPT_3 & 0.51 & SPS_3 & 0.53 \\
Avg. & $\mathbf{0 . 5 0}$ & Avg. & $\mathbf{0 . 5 6}$ \\
\hline
\end{tabular}

These results represent also a further validation of the quality of the mastic formed by the polymeric transparent binder and the finest part of the aggregates distribution.

An advanced mechanical characterization was based on evaluation of mixture behavior under dynamic load using the ITSM test carried out on 3 gyratory samples ( 80 gyrations) for each mixture at 3 different temperatures: 10,20 and $30^{\circ} \mathrm{C}$. According to the EN 12697-26 part C standard, the Modulus is determined through a pulse loading with a rise-time of $124 \mathrm{~ms}$, to generate a predefined horizontal deformation of $7 \pm 2 \mu \mathrm{m}$ in the core of the cylindrical specimen. The tests were carried out on 3 samples conditioned at 3 temperatures in order to verify the thermal sensitivity of the mixtures and how the presence of synthetic aggregates could affect this property.

The average results are presented in Figure 5 and summarized in Table 5. 


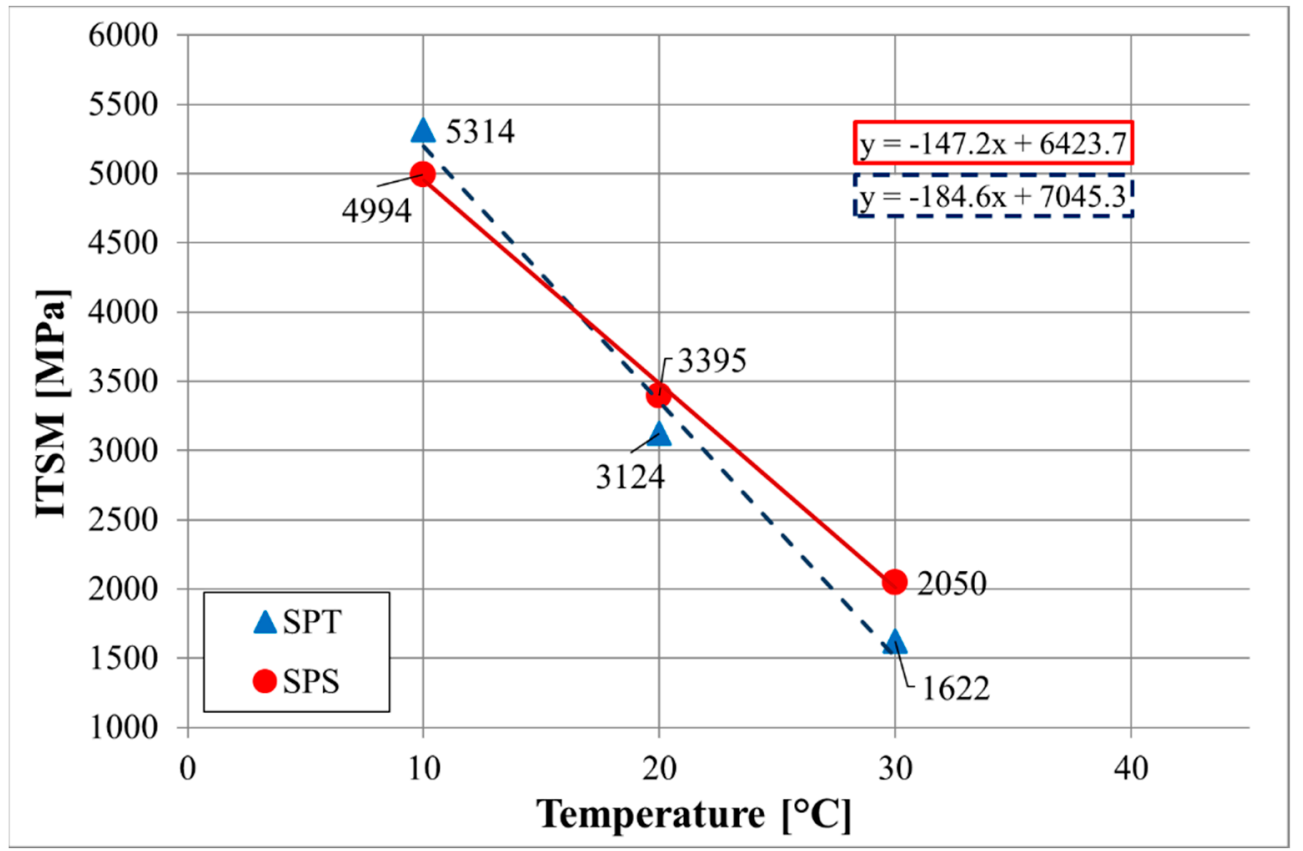

Figure 5. Average Indirect Tensile Stiffness Modulus (ITSM) results at 10,20 and $30^{\circ} \mathrm{C}$.

Table 5. ITSM test results.

\begin{tabular}{cccc}
\hline Mixture & ITSM @ $\mathbf{1 0}{ }^{\circ} \mathbf{C} \mathbf{~ ( M P a )}$ & ITSM $\left.@ \mathbf{2 0}{ }^{\circ} \mathbf{C} \mathbf{( M P a}\right)$ & ITSM @ 30 ${ }^{\circ} \mathbf{C}(\mathbf{M P a})$ \\
\hline SPT_1 & 5149 & 3034 & 1709 \\
SPT_2 & 5420 & 3109 & 1610 \\
SPT_3 & 5373 & 3230 & 1550 \\
Avg. SPT & $\mathbf{5 3 1 4}$ & $\mathbf{3 1 2 4}$ & $\mathbf{1 6 2 2}$ \\
SPS_1 & 4990 & 3416 & 2095 \\
SPS_2 & 4865 & 3368 & 2036 \\
SPS_3 & 5127 & 3402 & 2005 \\
Avg. SPS & $\mathbf{4 9 9 4}$ & $\mathbf{3 3 9 5}$ & $\mathbf{2 0 5 0}$ \\
\hline
\end{tabular}

As overall results, both mixtures show a consistent stiffness at each test temperature.

If $20^{\circ} \mathrm{C}$ is considered as the reference temperature, there are no substantial differences in stiffness between the two mixtures. The adopted technical specification does not suggest any limitations in terms of stiffness moduli. However, according to the scientific literature and real applications, the achievement of $3000 \mathrm{MPa}$ at $20^{\circ} \mathrm{C}$ can be considered as a suitable requirement for porous asphalts, considering their relatively weak structure.

In terms of thermal sensitivity, the two mixtures show a different variation in stiffness in relation to test temperature. The SPT mixture would appear to have a mechanical behavior that is more influenced by test temperature than the SPS mixture. Typically, for asphalt concretes an excessive stiffness at low temperatures and a low mechanical response at high temperatures could result in detrimental issues in terms of durability. In light of the above, the experimental mixture shows a positive increase in stiffness at high temperature and this could have a favorable effect in terms of rutting resistance. Still, the SPS mixture shows a stiffness trend line that corresponds to a reduced thermal sensitivity. This might be a consequence of the partial substitution of natural aggregates with synthetic materials. Future testing will assess the level of thermal transmittance for these artificial aggregates in order to validate this speculation. 


\subsection{Durability Evaluation: ITSR and Cantabro Tests}

Considering the porous structure of the material, the durability evaluation was based on the assessment of the water sensitivity of the mixtures, in terms of reduction in ITS and raveling resistance.

In the first case a set of 3 specimens for each mix were subjected to 10 freeze and thaw cycles, from -20 to $20^{\circ} \mathrm{C}$, for 5 days before being tested. In fact, moisture damage can be considered as one of the main forms of pavement deterioration, which is also promoted by the formation of ice [44]. According to well-established literature, high ITS and ITSR values could guarantee a good resistance to moisture damage [45]. According to the EN 12697-12, the reduction in ITS is calculated as the ratio between results obtained in wet and normal dry conditions (EN 12697-12).

The Cantabro test is typically used in Europe for evaluating the raveling resistance of porous asphalt concretes (EN 12697-17). The test enables the estimation of the abrasiveness of porous asphalt, as these mixtures have high air voids, the contact areas between aggregates, which guarantee cohesion of the asphalt concrete, are limited. It is worth noting that it does not reflect the abrasive effect by studded tires. Thus, the cohesion is evaluated in terms of particles loss (PL) when a set of Marshall samples (EN 12697-30, 50 blows per side) is placed in a Los Angeles machine for 300 revolutions, with a speed of 30 revolutions per minute. Four Marshall samples were tested for each mixture. In compliance with the standard, the specimens were stored for 2 days at a temperature of $25{ }^{\circ} \mathrm{C}$ prior to testing. Table 6 summarizes the results for ITSR and Cantabro tests.

Table 6. ITSR and Cantabro test results.

\begin{tabular}{ccccc}
\hline Mixture & ITS $_{\text {normal }}(\mathbf{M P a})$ & ITS $_{\text {wet }}(\mathbf{M P a})$ & ITSR (\%) & Particle Loss (\%) \\
\hline SPT_1 & 0.49 & 0.46 & $/$ & 3.3 \\
SPT_2 & 0.50 & 0.46 & $/$ & 3.5 \\
SPT_3 & 0.51 & 0.39 & $/$ & 3.3 \\
SPT_4 & $/$ & $/$ & $\mathbf{8 9}$ & 3.5 \\
Avg. SPT & $\mathbf{0 . 5 0}$ & $\mathbf{0 . 4 4}$ & $/$ & 3.3 \\
SPS_1 & 0.55 & 0.45 & $/$ & 3.9 \\
SPS_2 & 0.60 & 0.44 & $/$ & 3.8 \\
SPS_3 & 0.53 & 0.39 & $/$ & 3.4 \\
SPS_4 & $/$ & $/$ & $\mathbf{7 7}$ & 3.6 \\
Avg. SPS & $\mathbf{0 . 5 6}$ & $\mathbf{0 . 4 3}$ & & \\
\hline
\end{tabular}

The technical specifications generally suggest a minimum ITSR value equal to $75 \%$. Both experimental mixtures exceed this threshold value. It is worth noting that the reduction in ITS is generally evaluated for samples kept in a water bath $\left(40^{\circ} \mathrm{C}\right)$ for 72 hours prior testing. In the case under study, the ITSR results are in line with the suggested lower limit even if the mixtures have been subject to a considerable higher deterioration. The lower ITSR results for SPS are probably related to the higher air voids content that might had a detrimental effect during the freeze and thaw cycles.

In terms of particle loss, there is no significant difference between the two mixtures. The most common Italian technical specification suggests a maximum particle loss (PL) value equal to $20 \%$, for porous asphalt, which is substantially higher if compared to test results. This is a further validation of the quality of the cohesion between particles guaranteed by the polymeric transparent binder considering the remarkable porosity of the two mixtures.

\subsection{Functional Properties: Skid Resistance and Vertical Permeability Test}

Surface friction and vertical permeability are important functional properties for porous layers.

The friction between tires and road pavement involves two components: adhesion and hysteresis. The first phenomenon is connected to the microtexture of the pavement, which is generally evaluated by means of the skid resistance test [46]. The most common measure of the skid resistance is given in terms of Pendulum Test Value (PTV, EN 13036-4) using the British Portable Pendulum. According to the standard, the frictional force is the force acting tangentially in the contact area and it is measured 
as the loss of energy of a standard rubber slider that slides across the test surface. The PTV value in given by the average result of five repetitions for each single test point. The final result is adjusted with specific factors depending on the surface temperature. It is worth mentioning that the test surface must be wetted prior to testing.

As for the permeability, it is the most important property for a porous asphalt. According to the EN 12697-19, it can be evaluated in lab in terms of vertical and horizontal permeability: in this research, the former property was assessed. The vertical permeability is considered as the water flowing in a vertical direction through the specimen thickness. The test procedure imposes that a water column of constant height is kept on the surface of the porous sample and the vertical permeability is evaluated in terms of the amount of water flowing through the sample in a specific range of time using the Darcy's Law.

The results of both tests are shown in Table 7.

Table 7. Average Pendulum Test Value (PTV) and vertical permeability results.

\begin{tabular}{ccc}
\hline Mixture & PTV & Vertical Permeability $\left(\mathbf{1 0}^{-\mathbf{3}} \mathbf{~ m} / \mathbf{s}\right)$ \\
\hline SPT_1 & 53 & 0.50 \\
SPT_2 & 48 & 0.52 \\
SPT_3 & 49 & 0.63 \\
Avg. SPT & $\mathbf{5 0}$ & $\mathbf{0 . 5 5}$ \\
SPS_1 & 55 & 0.54 \\
SPS_2 & 55 & 0.54 \\
SPS_3 & 54 & 0.61 \\
Avg. SPS & $\mathbf{5 5}$ & $\mathbf{0 . 5 6}$ \\
\hline
\end{tabular}

In terms of skid resistance, a small difference was found between the two mixtures. The SPS mixture has a higher friction, possibly related to the different surface texture affected by the higher porosity and the different micro and macro texture of the synthetic aggregates. Both PTV values are acceptable but the surface texture needs to be improved if compared to values generally suggested by technical specifications for asphalt pavements (PTV $\geq 50)$. However, an increase in PTV is expected after a primary polishing of the binder film that covers the aggregates by the traffic. Nevertheless, an optimization of the grading distribution might improve the macro-texture of the material.

No significant difference was found in terms of vertical permeability for the two mixtures. It is worth noting that the reference standard suggests a minimum value of $0.5 \cdot 10^{-3} \mathrm{~m} / \mathrm{s}$ for traditional porous layers. The obtained values are remarkable, considering that the adopted gradation band is suggested for semi-porous layers. Nevertheless, taking into account the significant porosity of the two mixtures, the air voids interconnection must be improved. Future imaging tests with e.g. Nuclear Magnetic Resonance (NMR) technology will evaluate the inner structure of the samples in order to verify the interconnectivity and tortuosity of air voids.

\section{Conclusions}

In the present research, a low impact semi-porous concrete produced with transparent polymeric binder and pale limestone aggregates is proposed. To improve the sustainability of the material, an experimental mixture was produced with the partial substitution of natural aggregates with artificial ones obtained through the alkali-activation of waste basalt powder. The research program provided for a physical and mechanical laboratory characterization.

On the basis of the presented results, the following conclusions can be drawn:

- The adopted particles size distribution and polymeric binder amount allow the achievement of good workability and a higher porosity if compared to traditional semi-porous asphalt concretes. The presence of synthetic aggregates did not affect the mixing procedure and the workability properties of the mixture. The visual analysis of the samples and their inner structure highlighted a correct distribution of the artificial aggregates within the mixture. 
- The increased air voids content for the SPS mixture is more likely related to the rounded shape of the handcrafted particles, which limited the aggregates interlocking resulting in a more open structure.

- The mechanical characterization and durability evaluation highlighted how both mixtures exceed the threshold limits imposed by the technical specifications for semi-porous asphalt layer, despite the significant porosity of the materials. Consistent properties were registered in terms of water susceptibility considering the severe conditioning given by the freeze and thaw cycles. Furthermore, both mixtures revealed a ravelling resistance considerably lower than the threshold limit for porous asphalts, as a further confirmation of the good cohesion between particles guaranteed by the polymeric binder.

- The most relevant difference between the mixtures is related to the low thermal sensitivity of SPS. The experimental mixture showed a favourable increase in stiffness at high temperature and a slight decrease at the lowest ones. This phenomenon might be attributed to the presence of artificial aggregates. Future tests will assess the thermal transmittance of the synthetic aggregates in order to validate this conclusion.

- The two experimental mixtures showed a good vertical permeability which is in line with the lowest values suggested for porous layers. However, considering the high porosity of the mixture, most of the air voids may be not fully connected. In terms of skid resistance, both mixtures should be optimized to improve this parameter in their early life, despite the adoption of synthetic aggregates led to higher PTVs. As a general statement, the optimization of the mix design might improve the texture properties of the material as well as the interconnection of air voids.

In the light of the above, the use of transparent polymeric binder seems to be a viable solution for the production of low impact semi-porous layers for use in urban areas. Future studies will investigate the possible substitution of higher quantities of natural aggregate with synthetic material aiming to the production of $100 \%$ synthetic mixtures. Furthermore, the use of a centrifugal granulator can improve the quality of the synthetic aggregates and convert the production from the laboratory to the industrial scale.

Author Contributions: Conceptualization, P.T. and C.S.; investigation, P.T.; data curation, P.T. and C.S.; writing-original draft preparation, P.T. and C.S.; writing-review and editing, P.T. and C.S.; supervision, C.S.

Funding: This research received no external funding.

Acknowledgments: Authors are grateful to CORECOM s.r.l. that supplied the polymeric transparent binder during the whole research.

Conflicts of Interest: The authors declare no conflict of interest.

\section{References}

1. Artmann, M.; Inostroza, L.; Fan, P. Urban sprawl, compact urban development and green cities. How much do we know, how much do we agree? Ecol. Indic. 2019, 96, 3-9. [CrossRef]

2. Li, C.; Liu, M.; Hu, Y.; Shi, T.; Qu, X.; Walter, M.T. Effects of urbanization on direct runoff characteristics in urban functional zones. Sci. Total. Environ. 2018, 643, 301-311. [CrossRef] [PubMed]

3. Leopold, L.B. Hydrology for urban land planning - A guidebook on the hydrologic effects of urban land use. Circular 1968.

4. Whitford, V.; Ennos, A.R.; Handley, J.F. City form and natural process indicators for the ecological performance of urban areas and their alpplication to merseyside, uk.pdf. Landsc. Urban Plan. 2001, 57, 91-103. [CrossRef]

5. Huang, H.-J.; Cheng, S.-J.; Wen, J.-C.; Lee, J.-H. Effect of growing watershed imperviousness on hydrograph parameters and peak discharge. Hydrol. Process. 2008, 22, 2075-2085. [CrossRef]

6. Isik, S.; Kalin, L.; Schoonover, J.E.; Srivastava, P.; Lockaby, B.G. Modeling effects of changing land use/cover on daily streamflow: An Artificial Neural Network and curve number based hybrid approach. J. Hydrol. 2013, 485, 103-112. [CrossRef] 
7. Burant, A.; Selbig, W.; Furlong, E.T.; Higgins, C.P. Trace organic contaminants in urban runoff: Associations with urban land-use. Environ. Pollut. 2018, 242, 2068-2077. [CrossRef] [PubMed]

8. Brown, J.N.; Peake, B.M. Sources of heavy metals and polycyclic aromatic hydrocarbons in urban stormwater runoff. Sci. Total. Environ. 2006, 359, 145-155. [CrossRef] [PubMed]

9. Zhang, P.; Cai, Y.; Wang, J. A simulation-based real-time control system for reducing urban runoff pollution through a stormwater storage tank. J. Clean. Prod. 2018, 183, 641-652. [CrossRef]

10. Seto, K.C.; Güneralp, B.; Hutyra, L.R. Global forecasts of urban expansion to 2030 and direct impacts on biodiversity and carbon pools. Proc. Natl. Acad. Sci. USA 2012, 109, 16083-16088. [CrossRef]

11. Park, D.; Kang, H.; Jung, S.H.; Roesner, L.A. Reliability analysis for evaluation of factors affecting pollutant load reduction in urban stormwater BMP systems. Environ. Model. Softw. 2015, 74, 130-139. [CrossRef]

12. Sharior, S.; McDonald, W.; Parolari, A.J. Improved reliability of stormwater detention basin performance through water quality data-informed real-time control. J. Hydrol. 2019, 573, 422-431. [CrossRef]

13. Guan, M.; Sillanpää, N.; Koivusalo, H. Assessment of LID practices for restoring pre-development runoff regime in an urbanized catchment in southern Finland. Water Sci. Technol. 2015, 71, 1485. [CrossRef] [PubMed]

14. Mullaney, J.; Lucke, T. Practical review of pervious pavement designs. Clean Soil Air Water 2014, 42, 111-124. [CrossRef]

15. Ortega-Villar, R.; Lizárraga-Mendiola, L.; Coronel-Olivares, C.; López-León, L.D.; Bigurra-Alzati, C.A.; Vázquez-Rodríguez, G.A. Effect of photocatalytic Fe2O3 nanoparticles on urban runoff pollutant removal by permeable concrete. J. Environ. Manag. 2019, 242, 487-495. [CrossRef]

16. Zhenci, X.; Guo, Y. Simulation test of runoff on different underlying surfaces in urban area. South North Water Transf. Water Sci. Technol. 2017, 10, 64-66.

17. Zhu, H.; Yu, M.; Zhu, J.; Lu, H.; Cao, R.; Zhang, L. Simulation study on effect of permeable pavement on reducing flood risk of urban runoff. Int. J. Transp. Sci. Technol. 2018. [CrossRef]

18. Saadeh, S.; Ralla, A.; Al-Zubi, Y.; Wu, R.; Harvey, J. Application of fully permeable pavements as a sustainable approach for mitigation of stormwater runoff. Int. J. Transp. Sci. Technol. 2019. [CrossRef]

19. Kamali, M.; Delkash, M.; Tajrishy, M. Evaluation of permeable pavement responses to urban surface runoff. J. Environ. Manag. 2017, 187, 43-53. [CrossRef]

20. Higashiyama, H.; Sano, M.; Nakanishi, F.; Takahashi, O.; Tsukuma, S. Field measurements of road surface temperature of several asphalt pavements with temperature rise reducing function. Case Stud. Constr. Mater. 2016, 4, 73-80. [CrossRef]

21. Pisello, A.L. State of the art on the development of cool coatings for buildings and cities. Sol. Energy 2017, 144, 660-680. [CrossRef]

22. Praticò, F.G.; Giunta, M.; Marino, C.; Attinà, A. Pavement albedo and sustainability: An experimental investigation. In Proceedings of the 7th International Conference on Maintenance and Rehabilitation of Pavements and Technological Control, Auckland, New Zealand, 28-30 August 2012.

23. Starke, P.; Göbel, P.; Coldewey, W.G. Urban evaporation rates for water-permeable pavements. Water Sci. Technol. 2010, 62, 1161-1169. [CrossRef] [PubMed]

24. Takebayashi, H.; Moriyama, M. Study on Surface Heat Budget of Various Pavements for Urban Heat Island Mitigation. Adv. Mater. Sci. Eng. 2012, 2012, 1-11. [CrossRef]

25. Santamouris, M. Using cool pavements as a mitigation strategy to fight urban heat island-A review of the actual developments. Renew. Sustain. Energy Rev. 2013, 26, 224-240. [CrossRef]

26. Bao, T.; Liu, Z.; Zhang, X.; He, Y. A drainable water-retaining paver block for runoff reduction and evaporation cooling. J. Clean. Prod. 2019, 228, 418-424. [CrossRef]

27. Provis, J.L. Alkali-activated materials. Cem. Concr. Res. 2018, 114, 40-48. [CrossRef]

28. Duxson, P.; Fernández-Jiménez, A.; Provis, J.L.; Lukey, G.C.; Palomo, A.; Deventer, J.S.J. Geopolymer technology: The current state of the art. J. Mater. Sci. 2007, 42, 2917-2933. [CrossRef]

29. Tang, Z.; Li, W.; Hu, Y.; Zhou, J.L.; Tam, V.W. Review on designs and properties of multifunctional alkali-activated materials (AAMs). Constr. Build. Mater. 2019, 200, 474-489. [CrossRef]

30. Saraya, M.E.-S.I.; El-Fadaly, E. Preliminary Study of Alkali Activation of Basalt: Effect of NaOH Concentration on Geopolymerization of Basalt. J. Mater. Sci. Chem. Eng. 2017, 5, 58-76. 
31. Tataranni, P.; Besemer, G.M.; Bortolotti, V.; Sangiorgi, C. Preliminary Research on the Physical and Mechanical Properties of Alternative Lightweight Aggregates Produced by Alkali-Activation of Waste Powders. Materials 2018, 11, 1255. [CrossRef]

32. EN 1015-11, Methods of Test for Mortar for Masonry - Part 11: Determination of Flexural and Compressive Strength of Hardened Mortar; CEN (European Committee for Standardization): Brussels, Belgium, 1999.

33. EN 12697-31, Bituminous Mixtures - Test Methods for Hot Mix Asphalt. Part 31: Specimen Preparation by Gyratory Compactor; CEN (European Committee for Standardization): Brussels, Belgium, 2007.

34. EN 12697-23, Bituminous Mixtures - Test Methods for hot Mix Asphalt. Part 23: Determination of the Indirect Tensile Strength of Bituminous Specimens; CEN (European Committee for Standardization): Brussels, Belgium, 2018.

35. EN 12697-26, Bituminous Mixtures - Test Methods for Hot Mix Asphalt. Part 26: Stiffness; CEN (European Committee for Standardization): Brussels, Belgium, 2012.

36. EN 12697-12, Bituminous Mixtures - Test Methods for Hot Mix Asphalt. Part 12: Determination of the Water Sensitivity of Bituminous Specimens; CEN (European Committee for Standardization): Brussels, Belgium, 2018.

37. EN 12697-17, Bituminous Mixtures - Test Methods for Hot Mix Asphalt, Part 17: Particle Loss of Porous Asphalt Specimens; CEN (European Committee for Standardization): Brussels, Belgium, 2017.

38. EN 12697-19, Bituminous Mixtures - Test Methods for Hot Mix Asphalt, Part 19: Permeability of Specimens; CEN (European Committee for Standardization): Brussels, Belgium, 2012.

39. EN 13036-4, Road and Airfield Surface Characteristics - Test Methods. Part 4: Method for Measurement of Slip/Skid Resistance of a Surface: The Pendulum Test; CEN (European Committee for Standardization): Brussels, Belgium, 2011.

40. EN 12697-30, Bituminous Mixtures-Test Methods for Hot Mix Asphalt_Part 30: Specimen Preparation By Impact Compactor; CEN (European Committee for Standardization): Brussels, Belgium, 2012.

41. EN 12697-8, Bituminous Mixtures - Test Methods for Hot Mix Asphalt. Part 8: Determination of Void Characteristics of Bituminous Specimens; CEN (European Committee for Standardization): Brussels, Belgium, 2019.

42. EN 12697-6, Bituminous Mixtures - Test Methods for Hot Mix Asphalt. Part 6: Determination of Bulk Density of Bituminous Specimens; CEN (European Committee for Standardization): Brussels, Belgium, 2012.

43. Sangiorgi, C.; Tataranni, P.; Simone, A.; Vignali, V.; Lantieri, C.; Dondi, G. Waste bleaching clays as fillers in hot bituminous mixtures. Constr. Build. Mater. 2014, 73, 320-325. [CrossRef]

44. Sangiorgi, C.; Eskandarsefat, S.; Tataranni, P.; Simone, A.; Vignali, V.; Lantieri, C.; Dondi, G. A complete laboratory assessment of crumb rubber porous asphalt. Constr. Build. Mater. 2017, 132, 500-507. [CrossRef]

45. Chen, J.S.; Chen, S.F.; Liao, M.C. Laboratory and field evaluation of porous Asphalt concrete. Asian Transp. Stud. 2015, 3, 298-311.

46. Praticò, F.; Vaiana, R. A study on the relationship between mean texture depth and mean profile depth of asphalt pavements. Constr. Build. Mater. 2015, 101, 72-79. [CrossRef] 